\title{
Kejang Demam dan Faktor yang Mempengaruhi Rekurensi
}

\author{
Attila Dewanti, * Joanne Angelica Widjaja, ** Anna Tjandrajani, * Amril A Burhany * \\ *Kelompok Kerja Neurologi Anak, Rumah Sakit Anak dan Bunda Harapan Kita. \\ ** S1 Profesi, Fakultas Kedokteran Universitas Indonesia.
}

\begin{abstract}
Latar belakang. Kejang demam adalah penyakit yang sering dijumpai pada anak. Rekurensi kejang demam sering terjadi pada anak dan terdapat beberapa faktor yang mempengaruhinya. Faktor-faktor ini dapat membantu untuk meramalkan terjadinya rekurensi kejang demam pada pasien.

Tujuan. Mengetahui beberapa faktor yang mempengaruhi rekurensi kejang demam.

Metode. Desain penelitian kohort retrospektif. Data diambil dari rekam medis Rumah Sakit Anak dan Bunda Harapan Kita pada tahun 2008-2010. Responden penelitian adalah anak dengan kejang demam yang dirawat di rumah sakit.

Hasil. Terdapat 86 pasien dengan kejang demam, 41 (47,7\%) pasien di antaranya mengalami kejang demam berulang. Hasil penelitian mendapatkan rekurensi kejang demam terjadi 2,7 kali pada pasien yang menderita kejang pertama kali pada usia kurang dari 12 bulan, 3,2 kali pada pasien yang mempunyai riwayat keluarga dengan kejang demam, 4,4 kali pada pasien yang demam dengan suhu kurang dari $39^{\circ} \mathrm{C}$, dan 1,4 kali pada pasien dengan kejang demam kompleks.

Kesimpulan. Terdapat beberapa faktor yang mempengaruhi rekurensi kejang demam, di antaranya adalah suhu pasien ketika kejang, riwayat keluarga dengan kejang demam, usia pertama kali kejang, dan tipe kejang pasien. Sari Pediatri 2012;14(1):57-61.
\end{abstract}

Kata kunci: kejang, rekurensi

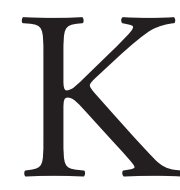

ejang demam adalah kejang yang disertai demam/terjadi pada kenaikan suhu tubuh (suhu rektal $>38^{\circ} \mathrm{C}$ ) yang Kejang demam merupakan salah satu penyakit

\section{Alamat korespondensi:}

Dr. Attila Dewanti, Sp.A, Staf Divisi Neurologi Anak RS Anak dan Bunda Harapan Kita Jakarta, Jl. Letjen S. Parman Kav. 87, Slipi. Telp. (021) 5668284 yang sering terjadi pada anak. Kejang demam umumnya terjadi pada anak yang berusia 6 bulan sampai 5 tahun. Kejang demam merupakan kelainan neurologis yang paling sering dijumpai pada anakanak, terutama pada golongan umur 3 bulan sampai 5 tahun. ${ }^{1,2}$ Kejang demam dikelompokkan menjadi dua, yaitu kejang demam sederhana dan kejang demam kompleks. ${ }^{3}$

Setelah kejang demam pertama, 33\% anak akan mengalami satu kali rekurensi (kekambuhan), dan 9\% anak mengalami rekurensi 3 kali atau lebih. ${ }^{4}$ Beberapa 
penelitian mengatakan rekurensi dari kejang demam akan meningkat jika terdapat faktor risiko seperti kejang demam pertama pada usia kurang dari 12 bulan, terdapat riwayat keluarga dengan kejang demam, dan jika kejang pertama pada suhu $<40^{\circ} \mathrm{C}$, atau terdapat kejang demam kompleks.,

Lennox-Buchthal dalam Kjeldsen $\mathrm{dkk}^{7}$ dan Pal $\mathrm{dkk}^{8}$ berpendapat bahwa kepekaan terhadap bangkitan kejang demam diturunkan oleh sebuah gen dominan dengan penetransi yang tidak sempurna. Lennox berpendapat bahwa $41,2 \%$ anggota keluarga penderita mempunyai riwayat kejang sedangkan pada anak normal hanya $3 \%$.

Prognosis kejang demam baik, namun bangkitan kejang demam membawa kekhawatiran yang sangat bagi orang tuanya. ${ }^{9}$ Di India, hasil penelitian Parmar $\mathrm{dkk}^{10}$ melaporkan $77,9 \%$ orang tua pasien kejang demam tidak mempunyai pengetahuan tentang kejang demam dan $90 \%$ menganggap anaknya akan meninggal. Maka atas dasar pertimbangan kekhawatiran dan kebingungan orang tua terhadap anaknya ketika mengalami bangkitan kejang, maka diperlukan tindakan pencegahan terhadap berulangnya bangkitan kejang demam tersebut.

Tujuan dari penelitian ini mencoba untuk melakukan evaluasi faktor-faktor risiko yang berperan dalam terjadinya rekurensi kejang demam. Penelitian ini bermanfaat secara ilmiah untuk melakukan upaya promotif dan preventif kepada orang tua untuk menurunkan risiko terjadinya bangkitan kejang demam berulang.

\section{Metode}

Penelitian dengan rancangan kohort retrospektif, dilakukan di RSAB Harapan Kita selama periode tahun 2008-2010. Kriteria inklusi kelompok kasus adalah semua anak dibawah usia 5 tahun, kejang berhubungan dengan demam (suhu tubuh $>38^{\circ} \mathrm{C}$ ), pasien baru maupun lama, dan orang tua/wali bersedia diikutsertakan dalam penelitian. Kriteria eksklusi kelompok kasus adalah pada pemeriksaan fisik dicurigai ada infeksi intrakranial, gangguan metabolik dan elektrolit, menggunakan obat anti konvulsan jangka panjang, serebral palsi, dan data tidak lengkap.

Penelitian mencakup 86 pasien. Pengumpulan data dimulai dengan memilih pasien dengan bangkitan kejang demam yang memenuhi kriteria penelitian, kemudian dicatat data klinis, catatan medik dan wawancara dengan orang tua pasien. Pengolahan data dilakukan secara deskriptif dan dengan menggunakan SPSS 11.5.

\section{Hasil}

Didapatkan 86 pasien kejang demam di RSAB Harapan Kita pada tahun 2008-2010, dengan data yang lengkap serta dapat dilakukan follow up. Empatpuluh satu (47,7\%) pasien mengalami rekurensi kejang demam. Tabel 1 memperlihatkan bahwa pasien yang mengalami rekurensi kejang demam terbanyak pada usia $0-12$ bulan yaitu $23,5 \%$, sedangkan pada

Tabel 1. Karakteristik pasien kejang demam

\begin{tabular}{lcc}
\hline & $\begin{array}{c}\text { Kasus (kambuh) } \\
\mathrm{n}(\%)\end{array}$ & $\begin{array}{c}\text { Kontrol } \\
\mathrm{n}(\%)\end{array}$ \\
\hline $\begin{array}{l}\text { Usia pertama kali kejang (bulan) } \\
0-12\end{array}$ & $20(23,5)$ & $14(16,2)$ \\
$\quad>12$ & $21(24,4)$ & $31(35,9)$ \\
$\begin{array}{l}\text { Jenis kelamin } \\
\text { Laki-laki }\end{array}$ & $19(22,0)$ & $21(24,4)$ \\
$\quad$ Perempuan & $22(25,6)$ & $24(27,9)$ \\
Riwayat keluarga & & \\
$\quad$ Positif & $10(11,6)$ & $4(4,6)$ \\
$\quad$ Negatif & $31(36,0)$ & $41(47,7)$ \\
Suhu ${ }^{\circ} \mathrm{C}$ & & $22(25,6)$ \\
$\quad<39$ & $20(23,2)$ & $23(26,7)$ \\
$>39$ & $21(24,4)$ & $37(43,0)$ \\
Tipe kejang demam & & $8(17,3)$ \\
$\quad$ KDS & $32(37,2)$ & \\
KDK & $9(10,4)$ & \\
\hline
\end{tabular}


pasien yang tidak mengalami rekurensi usia kejang demam pertama terbanyak pada usia $13-36$ bulan 29\%. Hal tersebut menunjukkan jenis kelamin pasien baik yang mengalami rekurensi kejang demam maupun yang tidak mengalami rekurensi, sebagian besar adalah laki-laki, yaitu 25,6\% dan 27,9\%.

Terdapat riwayat kejang pada keluarga pasien sebesar $16,2 \%$, yaitu $11,6 \%$ pada pasien yang mengalami rekurensi kejang demam dan 4,6\% pasien yang tidak mengalami rekurensi kejang demam. Sebanyak 51,1\% pasien mengalami kejang ketika suhu pasien lebih dari $39^{\circ} \mathrm{C}$. Secara umum tipe kejang demam pada pasien, $37,2 \%$ yang mengalami rekurensi kejang demam dan 43,0\% yang tidak mengalami rekurensi kejang demam, merupakan kejang demam simpleks

Anak dengan usia pertama kali kejang kurang dari 12 bulan lebih rentan mengalami rekurensi kejang demam, 2,7 kali dibandingkan dengan anak yang mengalami kejang demam pada usia lebih dari 12 bulan. Anak dengan riwayat keluarga kejang mempunyai 3,2 kali kemungkinan untuk mengalami rekurensi kejang demam kembali. Anak yang kejang pada suhu kurang dari $39^{\circ} \mathrm{C}$, dan dengan tipe kejang demam kompleks mempunyai 4,4 kali, dan 1,4 kali kemungkinan untuk mengalami rekurensi kejang demam kembali (Tabel 3).

Tabel 2. Univariat analisis

\begin{tabular}{lcc}
\hline Variabel & OR & $95 \%$ CI \\
\hline Usia pertama kali kejang $<12$ bulan & 1,98 & $0,8-4,9$ \\
Jenis kelamin & 0,99 & $0,4-2,3$ \\
Riwayat keluarga & 3,31 & $0,9-11,5$ \\
Suhu $<39^{\circ} \mathrm{C}$ & 2,99 & $0,5-16,3$ \\
Tipe kejang demam kompleks & 1,93 & $0,8-4,7$ \\
\hline
\end{tabular}

Tabel 3. Multivariat analisis

\begin{tabular}{lcc}
\hline Variabel & OR & $95 \%$ CI \\
\hline Usia pertama kali kejang $<12$ bulan & 2,7 & $1,001-7,265$ \\
Riwayat keluarga & 3,2 & $0,892-13,837$ \\
Suhu $<39^{\circ} \mathrm{C}$ & 4,4 & $0,752-26,204$ \\
Tipe kejang demam: kompleks & 1,4 & $0,528-3,771$ \\
\hline
\end{tabular}

\section{Pembahasan}

Terdapat faktor-faktor yang berperan dalam terjadinya rekurensi kejang demam pada anak. Dari hasil penelitian didapatkan bahwa anak dengan usia kejang demam pertama kali sebelum usia 12 bulan mempunyai kemungkinan untuk mengalami kejang demam kembali 2,7 kali lebih besar daripada anak yang mengalami kejang demam pertama pada usia lebih dari 12 bulan. Penelitian yang telah dilakukan oleh Verity dkk, ${ }^{11}$ Reza $\mathrm{dkk}^{4}$ menunjukkan hal yang sama bahwa rekurensi dari kejang demam meningkat pada anak yang mengalami kejang demam pada usia lebih muda. Demikian juga dengan penelitian yang dilakukan oleh Pavlidou $\mathrm{dkk}^{12}$ mendapatkan anak dengan usia muda lebih mudah mengalami kejang demam berulang.

Pada usia kurang dari 12 bulan, keadaan otak belum matang, reseptor untuk asam glutamate baik inotropik maupun metabotropik sebagai reseptor eksitator padat dan aktif, sebaliknya reseptor GABA sebagai inhibitor kurang aktif, sehingga pada otak yang belum matang eksitasi lebih dominan disbanding inhibisi. Corticotropin releasing hormone (CRH) merupakan neuropeptid eksitator, berpotensi sebagai prokonvulsan. Pada otak yang belum matang kadar CRH di hipokampus tinggi, berpotensi terjadi bangkitan kejang apabila terpicu oleh demam. Mekanisme homeostasis pada otak belum matang masih lemah, akan berubah sejalan dengan perkembangan otak dan pertambahan umur, oleh karena pada otak belum matang neural $\mathrm{Na}^{+} / \mathrm{K}^{+}$ATP ase masih kurang. Pada otak yang belum matang regulasi ion $\mathrm{Na}^{+}, \mathrm{K}^{+}$, dan $\mathrm{Ca}^{++}$belum sempurna, sehingga mengakibatkan gangguan repolarisasi pasca depolarisai dan meningkatkan eksitabilitas neuron. ${ }^{13}$ Oleh karena itu pada masa otak belum matang mempunyai eksitabilitas neural lebih tinggi dibandingkan otak yang sudah matang, sehingga pada masa ini rentan terhadap bangkitan kejang. ${ }^{13}$

Tidak ada perbedaan signifikan terhadap rekurensi kejang demam menurut jenis kelamin. Hal tersebut juga didapatkan pada penelitian yang dilakukan oleh Verity $\mathrm{dkk}^{11}$ dan Chung dkk. ${ }^{14}$

Rekurensi kejang demam 3,2 kali lebih banyak pada anak dengan riwayat kejang di keluarga. Penelitian yang dilakukan oleh Verity dkk dan Reza $\mathrm{dkk}^{4,11}$ juga menunjukkan hal yang sama. Peneliti lain mendapatkan bahwa rekurensi kejang meningkat pada anak dengan onset awal lebih muda dan juga pada anak dengan riwayat keluarga kejang demam. ${ }^{15}$

Rekurensi kejang demam berkaitan dengan jenis kelamin, infeksi pernafasan, riwayat keluarga yang 
positif dan berat badan lahir ${ }^{16}$ dan peningkatan risiko terjadinya kejang demam terjadi pada anak yang mempunyai saudara kandung dengan riwayat kejang demam. ${ }^{17}$ Peneliti lain membuktikan bahwa kejang demam dalam keluarga dekat merupakan faktor yang signifikan dalam risiko berulangnya kejang. ${ }^{18-20}$

Keluarga dengan riwayat pernah kejang demam sebagai faktor risiko untuk terjadinya kejang demam adalah kedua orang tua ataupun saudara sekandung (first degree relative). Belum dapat dipastikan cara pewarisan sifat genetik terkait dengan kejang demam, apakah autosomal resesif atau autosomal dominan. Penetransi autosomal dominan diperkirakan sekitar 60\%-80\%. ${ }^{21}$ Bila kedua orang tuanya tidak mempunyai riwayat pernah menderita kejang demam maka risiko terjadinya kejang demam hanya 9\%. Apabila salah satu orang tua pasien dengan riwayat pernah kejang demam mempunyai risiko untuk terjadi bangkitan kejang demam 20\%-22\%. Apabila kedua orang tua pasien tersebut mempunyai riwayat pernah menderita kejang demam maka risiko untuk terjadinya bangkitan kejang demam meningkat menjadi 59\%$64 \% .{ }^{22}$ Kejang demam diwariskan lebih banyak oleh ibu dibandingkan ayah, 27\% berbanding 7\%.

Kami mendapatkan bahwa anak dengan suhu $<39^{\circ} \mathrm{C}$ pada saat kejang mempunyai kemungkinan 4,4 kali lebih besar mengalami rekurensi kejang dibandingkan dengan anak yang kejang dengan suhu $>39^{\circ} \mathrm{C}$.

Beberapa penelitian lain juga menunjukkan hal yang sama, tingkat pireksia yang diderita oleh anak akan mempengaruhi rekurensi terjadinya kejang demam. ${ }^{23-25}$ Diperkuat oleh penelitian lain yang dilakukan oleh El Radhi dkk ${ }^{26}$ didapatkan anak dengan suhu tubuh yang tidak terlalu tinggi $\left(<39^{\circ} \mathrm{C}\right)$ pada saat kejang demam pertama akan lebih mudah untuk kejang kembali bila anak tersebut menderita panas. Suhu yang rendah pada saat kejang pertama berpengaruh terhadap rekurensi juga ditunjukkan pada penelitian Tanjung. ${ }^{25}$ Sedangkan penelitian yang dilakukan oleh Reza $\mathrm{dkk}^{4}$ mengatakan bahwa tidak ada hubungan antara suhu saat kejang dengan terjadinya rekurensi kejang demam.

Rekurensi kejang demam 1,4 kali lebih banyak pada anak dengan riwayat kejang demam kompleks. Haltersebut sesuai dengan penelitian yang dilakukan oleh Habib dkk ${ }^{27}$ yang mendapatkan anak dengan kejang demam kompleks lebih besar kemungkinan menderita kejang demam berulang.

\section{Kesimpulan}

Terdapat beberapa faktor yang mempengaruhi rekurensi kejang demam, di antaranya adalah suhu pasien ketika kejang, riwayat keluarga dengan kejang demam, usia pertama kali kejang dan tipe kejang pasien. Perlu dilakukan penelitian selanjutnya dengan jumlah subyek yang lebih besar serta mengikutsertakan variabel-variabel lain yang belum diteliti untuk memperoleh hasil yang lebih akurat. Kekurangan dari penelitian kami adalah penggunaan data retrospektif yang sudah tertulis, dan jumlah pasien yang diteliti belum terlalu banyak.

\section{Daftar pustaka}

1. Shinnar S. Febrile seizures. Swaiman KF, Ashwal S, Ferriero D, penyunting. Pediatric Neurology: principles \& practice. Edisi ke 4. Philadelphia: Mosby Elsevier; 2006.h.1078-86.

2. Leung AK, Robson WL. Febrile seizures. J Pediatr Health Care 2007;21:250-5.

3. Johnson MV. Febrile seizure. Behrman RE, Kliegman RM, Jenson H, penyunting. Nelson Textbook of Pediatrics. Edisi ke 18. Philadelphia: Saunders; 2007.h. 2457-580.

4. Reza M, Eftekhaari TE, Farah M. Febrile seizures: Faktors affecting risk of recurrence. J Pediatr Neurol 2008; 6 341-4.

5. Waruiru C, Appleton R. Febrile seizures: an update. Arch Dis Child 2004;89:751-6.

6. Bessisso MS, Elsaid MF, Almula NA, Kadomi NK, Zeidan SH, Azzam SB, dkk. Recurrence risk after a first febrile convulsion. Saudi Med J 2001;22:254-8.

7. Kjeldsen MJ, Corey LA, Solaas MH. Genetic factors in seizures: a population based study of 47.626 US, Norwegian and Danish twin pairs. Twin res hum genet 2005;8138-47.

8. Pal DK, Kugler SL, Mandelbaum DE, Durner M. Phenotypic features of familial febrile seizures: casecontrol study. Neurology 2003; 60:410-4.

9. Knudsen FU. Febrile seizures: treatment and prognosis. Epilepsia 2000;41:2-9.

10. Parmar RC, Sahu DR. Bavdekar SB. Knowledge attitude and practices of parents of children with febrile convulsion. J postgrad Med 2001;47:19-23.

11. C.M. Verity, N.R. Butler and J. Golding, Febrile convulsions in a national cohort followed up from birth. II-Medical history and intellectual ability at 5 years 
of age. Diunduh dari: http://www.jstor.org/pss/29519078. Diakses pada tanggal 3 Januari 2011.

12. Pavlidou E, Tzitiridou M, kontopoulos E, Panteliadis CP. Which factors determine febrile seizure recurrence? A prospective study. Brain dev 2008;30:7-13.

13. Chen Y, Beder RA, Baram TZ. Novel and transient population of corticotrophin releasing hormone expressing neurons in developing hippocampus suggest unique functional roles: a quantitative spatiotemporal analysis. J Neurosc;15:7171-81

14. Chung B, Wat LC, Wong V. Febrile seizures in southern Chinese children: incidence and recurrence. Pediatr Neurol 2006;34:121-6.

15. Martin-Fernandez JJ, Molto-Jorda JM, Villaverde R, Salmeron P, Prieto-Munoz I, Fernández-Barreiro A. Risk factors in recurrent febrile seizures. Rev Neurol 1996;24:1520-4.

16. Talebian A, Mohammadi M. Febrile seizure: recurrence and risk factors. Iran J Child Neurol 2006;1:43-8.

17. Siddiqui TS. Febrile convulsions in children: relationship of family history to type of convulsions and age at presentation. J Ayub Med Coll Abbottabad 2002;14:26-8.

18. Durá-Travé T, Yoldi-Petri ME. A long-term followup of 234 children with febrile seizures. Rev Neurol 2004;39:1104-8.

19. Jones T, Jacobsen SJ. Childhood febrile seizures: overview and implications. Int J Med Sci 2007;4:110-14.

20. Karande S. Febrile seizures: A review for family physicians. Indian J Med Sci 2007;61:161-72.

21. Singh R, Sceffer IE, Crossland K, Bercovic SF. Generalized epilepsy with febrile seizure plus: A common childhood-onset genetic epilepsy syndrome. Ann Neurol 1999;45:75-81.

22. Menkes JH, Sankar R. Paroxysmal Disorders. Dalam: Menkes JH, Sarnat BH, penyunting. Child neurology. Edisi ke-6. Philadelphia: Lippincott Williams \& Wilkins JR; 2000.h.987-91.

23. Fetveit A. Assessment of febrile seizures in children. Eur J Pediatr 2008;167:17-27.

24. Armon K, Stephenson T, MacFaul R, Hemingway P, Werneke U, Smith S. An evidence and consensus based guideline for the management of a child after a seizure. Emerg Med J 2003;20:13-20.

25. Tanjung C, Mangunatmadja I, Sastroasmoro S, Budiman I. Predictors for the recurrent febrile seizures after the first complex febrile seizures. Paediatr Indones 2006;46: 204-8.

26. El-Radhi AS, Barry W. Do antipyretics prevent febrile convulsion? Arch Dis Child 2003;88:641-2.

27. Habib Z, Akram S, Ibrahim S, Hasan B. febrile seizure: factors affecting risk of recurrence in Pakistani children presenting at the Aga Khan University hospital. J Pak Med Assoc 2003;53:11-7. 